\title{
A POLÍTICA NACIONAL DE DESENVOLVIMENTO REGIONAL - PNDR E OS FUNDOS CONSTITUCIONAIS DE FINANCIAMENTO
}

\section{THE NATIONAL POLICY OF REGIONAL DEVELOPMENT - PNDR AND THE CONSTITUTIONAL FINANCING FUNDS}

\author{
Fernando Cezar de Macedo \\ Universidade Estadual de Campinas - Campinas - SP - Brasil \\ Vitarque Lucas Paes Coelho \\ Ministério da Integração Nacional - Brasilia - DF - Brasil
}

\begin{abstract}
Resumo: O presente artigo analisa as aplicações dos Fundos Constitucionais de Financiamento no sentido de verificar sua aderência aos princípios estabelecidos pela Política Nacional de Desenvolvimento Regional - PNDR. A partir da investigação realizada, constatou-se pouca relação entre a operação dos fundos constitucionais e os postulados da PNDR. Mesmo após a edição do Decreto 6.047/2007, que institucionaliza a política, não se verificou mudança de comportamento da aplicação dos fundos constitucionais, cuja operação continuou voltada para aqueles espaços mais dinâmicos das regiões estudadas. As conclusões indicam a necessidade de aperfeiçoar as atuais normativas que regem esses Fundos de modo a induzir estes instrumentos a uma ação consistente de desenvolvimento regional que auxilie na transformação econômica das regiões beneficiadas.
\end{abstract}

Palavras-chave: PNDR. Fundos Constitucionais de Financiamento. Desenvolvimento Regional.

Abstract: This article analyzes the Constitutional Financing Funds applications aiming to verify its adherence to the principles determined by the National Policy of Regional Development - PNDR. From the research carried out, little correlation was found between the constitutional funds operation and PNDR postulates. Even after the Decree $6047 / 2007$ issue, which institutionalizes the policy, no change in the constitutional funds application pattern was found, which operation continued directed to the most dynamic spaces of the studied regions. The conclusions indicate the need to improve the current regulations governing these Funds in order to induce these instruments to a consistent regional development action that helps in the benefited regions economic transformation. 
Keywords: PNDR. Constitutional Financing Funds. Regional Development.

\section{APRESENTAÇÃO}

O presente artigo analisa as aplicações dos Fundos Constitucionais de Financiamento com o objetivo de verificar sua aderência aos princípios estabelecidos pela PNDR. Encontra-se dividido em quatro partes, além desta apresentação e das considerações finais. $\mathrm{Na}$ primeira, discute-se brevemente a questão do desenvolvimento regional e o papel dos fundos públicos no Brasil. Na segunda, apresenta-se a PNDR; na terceira, a relação dessa política com os Fundos Constitucionais de Financiamento; na quarta, faz-se uma avaliação desses Fundos, considerando-se o papel dos bancos públicos que o administram. 
de...

\section{INTRODUÇÃO: DESENVOLVIMENTO REGIONAL E FUNDOS PÚBLICOS NO BRASIL}

A histórica persistência dos desequilíbrios regionais no Brasil sempre foi a justificativa para a constituição de políticas regionais sustentadas por fundos públicos, com objetivo de alavancar o desenvolvimento e a diversificação produtiva das áreas pejorativamente denominadas, no passado, de "regiões-problema"1. Essa percepção também se fez presente na última assembleia nacional constituinte quando, tanto a questão regional quanto a questão federativa, foram objetos de debates que culminaram no artigo 159 da Constituição Federal de 1988 que foi determinante para a criação dos Fundos Constitucionais de Financiamento. Desde a regulamentação em 1989, esses Fundos tornaram-se peça-chave no financiamento da política regional brasileira e, atualmente, são a principal fonte de recursos para a execução da PNDR.

Criados com o objetivo de contribuir para o desenvolvimento socioeconômico das regiões-alvo a partir do estímulo aos setores produtivos, os recursos desses três fundos são repassados pela Secretaria do Tesouro Nacional - STN para o Banco do Nordeste, no caso do Fundo Constitucional de Financiamento do Nordeste - FNE, para o Banco da Amazônia Fundo Constitucional de Financiamento do Norte FNO e para o Banco do Brasil Fundo Constitucional de Financiamento do Centro-Oeste - (FCO) que os operacionalizam e os administram em cada macrorregião. Eles podem ser aplicados em programas de financiamento de acordo com os planos regionais de desenvolvimento e, segundo normativa, visam a atender preferencialmente "[...] projetos de atividades produtivas de mini e pequenos produtores rurais e de micro e pequenas empresas; as atividades que utilizem intensivamente matérias-primas e mão de obra locais; e a produção de alimentos básicos para a população" (BRASIL -MINISTÉRIO DA INTEGRAÇÃO, 2007).

\footnotetext{
1 Não se concorda aqui com o termo pejorativo "região-problema", razão pela qual ele se encontra entre aspas. Se o mesmo é utilizado é porque ficou consagrado na literatura e deixa claro do se está tratando. Se a questão regional diz respeito à relação dialética parte-todo, o problema está tanto nas partes quanto no todo, ou seja, tratase do problema do subdesenvolvimento brasileiro cuja expressão fenomênica, do ponto de vista espacial, são os desequilíbrios urbano-regionais.
}

Redes (St. Cruz Sul, Online), v. 20, n 3 - Suplemento, p. 464 - 486, set./dez. 2015466 
Constituem fontes de recursos dos três Fundos: i) 3\% do valor da arrecadação do imposto sobre renda e proventos de qualquer natureza e do imposto sobre produtos industrializados, entregues pela União, na forma do art.159, inciso I, alínea c da Constituição Federal, sendo 0,6\% para o $\mathrm{FNO}, 1,8 \%$ para o $\mathrm{FNE}$ (alocado igualmente para a região do Semiárido e para o restante da região fora dele) e 0,6\% para o FCO; ii) os retornos e resultados de suas aplicações; iii) o resultado da remuneração dos recursos momentaneamente não aplicados, calculado com base em indexador oficial; iv) contribuições, doações, financiamentos e recursos de outras origens, concedidos por entidades de direito público ou privado, nacionais ou estrangeiras; v) dotações orçamentárias ou outros recursos previstos em lei².

O FNO, o FNE e o FCO são, portanto, "fundos públicos de poupança compulsória regional, enquanto entidades públicas de natureza contábil-financeira, com fontes de recursos oriundas em impostos e destinação exclusiva sob a forma de operações de crédito" (CINTRA, 2007, p.3). Juntamente com os Fundos de Desenvolvimento Regional, os Fundos Fiscais de Financiamento e dos incentivos fiscais, eles são instrumentos para financiamento das políticas de desenvolvimento regional no país, executadas pelo Ministério da Integração Nacional- MI.

Costa (2011), em monografia que analisa para o ano de 2009 o patrimônio de 83 fundos federais, apresenta a relação dos dez maiores, o que nos dá uma ideia bastante razoável do volume de recursos disponíveis para que cada um deles atinja seus objetivos. Nela, considerando o patrimônio bruto, fica evidente a importância e o tamanho - do FNE ( $5^{\circ}$ maior), do FCO $\left(8^{\circ}\right)$ e FNO $\left(9^{\circ}\right)$-, conforme se observa no Quadro 1.

Quadro 1. Fundos federais: patrimônio bruto e líquido dos 10 mais relevantes

\begin{tabular}{|c|c|c|c|}
\hline Ranking & Fundo & $\begin{array}{c}\text { Patrimônio Bruto em } \\
\mathbf{3 1 / 1 2 / 2 0 0 9} \\
\text { (R\$ bilhões) }\end{array}$ & $\begin{array}{c}\text { Patrimônio Líquido em } \\
\mathbf{3 1 / 1 2 / 2 0 0 9} \\
\text { (R\$ bilhões) }\end{array}$ \\
\hline 1 & FGTS & 235,06 & 30,49 \\
\hline 2 & FAT & 162,06 & 159,8 \\
\hline
\end{tabular}

2 Fonte: www.integracao.gov.br. 
de...

\begin{tabular}{|c|c|c|c|}
\hline 3 & FCVS & 92,49 & $(84,52)$ \\
\hline 4 & PIS - PASEP & 35,63 & 33,99 \\
\hline 5 & FNE & 29,42 & 29,42 \\
\hline 6 & FGE & 13,36 & 13,34 \\
\hline 7 & FAR & 13,02 & 4,63 \\
\hline 8 & FCO & 11,51 & 11,51 \\
\hline 9 & FNO & 10,17 & 10,15 \\
\hline 10 & FMM & 9,54 & 8,94 \\
\hline
\end{tabular}

Fonte: Costa (2011).

Se o problema regional brasileiro persiste, deve-se muito mais a fatores históricos e outros de natureza socioeconômica e política, tradicionalmente tratados na literatura. $O$ volume de recursos disponíveis para a política regional pode não ser suficiente, mas de forma alguma pode ser considerado pouco, especialmente porque vem crescendo desde 2003, conforme destacaram Macedo et al (2015). Não se pode, portanto, atribuir a manutenção do histórico desequilíbrio regional do país exclusivamente à insuficiência financeira. Outros determinantes estruturais que estão na raiz de nossa formação econômica e socioespacial, a pactuação política intra e interelites regionais, a forma de integração produtiva de nossas regiões e a maneira como se estrutura nosso pacto federativo, ajudam a explicar a questão regional brasileira.

Do ponto de vista normativo, observa-se a necessidade de aperfeiçoar as atuais diretivas que regem esses Fundos de modo a induzi-los a efetivamente tornarem-se instrumentos para uma ação consistente de desenvolvimento regional que auxilie na transformação econômica das regiões beneficiadas, conforme será discutido nos itens 3 e 4. 


\section{POLÍTICA DE DESENVOLVIMENTO REGIONAL NO BRASIL: DA DERROCADA À PNDR}

Há certo consenso na literatura pertinente de que as políticas de desenvolvimento regional no Brasil entraram em derrocada nos anos 1980, com o enfraquecimento do governo federal e o declínio, do ponto de vista teórico e ideológico, da centralidade da escala nacional como lócus mais importante de formulação de políticas. Dada a crise do Estado, a partir daquela década, com o neoliberalismo dos anos 1990 e os impasses do pacto federativo, tornou-se muito comum a defesa das políticas subnacionais de desenvolvimento contra a velha forma de planejamento regional centralizado e determinado a partir da esfera federal. A crítica residia na interpretação de que as políticas federais eram formuladas e implementadas "de cima para baixo" e tinham na escala nacional sua determinação principal, muitas vezes, sem levar em conta as especificidades regionais.

Naquele cenário, fortaleceram-se as ações localistas que visavam atrair para os seus espaços o capital que se movimentava mais livre de amarras dado os processos de abertura que se verificavam alhures, especialmente nos países subdesenvolvidos latino-americanos, com o aprofundamento da globalização. As políticas urbanas e regionais passaram a ser pensadas atomisticamente, seguindo receituário propugnado pela literatura internacional, muitas vezes, atendendo às exigências de organismos multilaterais como o Banco Mundial. Dissociadas de qualquer projeto pretensamente nacional, essas políticas de base local eram vistas como instrumentos para construção dos determinantes capazes de habilitar os lugares para o aproveitamento das "janelas de oportunidades" que se verificariam com a globalização. Logo, atrair investimentos seria um fim em si mesmo, pois garantiria a aderência dos espaços locais à economia global em mutação, razão pela qual o Brasil abriu sua economia indiscriminadamente na última década do século XX: no auge do neoliberalismo no país, era clara a tentativa de tornar-se atrativo ao capital internacional. Com a crise federativa e os ajustes macroeconômicos verificados que diminuíram o raio de manobra do governo federal, ampliaram-se as ações subnacionais, especialmente 
aquelas derivadas da "guerra fiscal"3, subjugando qualquer perspectiva de ações de política regional articuladas nacionalmente.

A partir de 2003, com a PNDR, o governo federal assume que o problema regional não pode ser tratado exclusiva ou mesmo majoritariamente pela ótica localista que preconiza o desenvolvimento "de baixo para cima", prioriza a escala local e desconsidera o protagonismo do Estado nacional. Tampouco pode ser superado por meio da velha política centralizadora nacional que caracterizou a criação da Superintendência do Desenvolvimento do Nordeste - SUDENE e Superintendência do Desenvolvimento da Amazônia - SUDAM e que resultou na implantação de uma série de "enclaves" regionais.

Com base na PNDR, a questão regional passaria a ser pensada e trabalhada - pelo menos retoricamente, pois na prática isso não necessariamente se verificaria - a partir de múltiplas escalas (a local, a microrregional, a mesorregional, a macrorregional, a nacional, a faixa de fronteira, o semiárido, as Regiões Integradas de Desenvolvimento RIDES, etc.) nas quais devem atuar o poder público, levando-se em conta as especificidades das regiões.

Segundo o documento original,

a PNDR exige uma abordagem das desigualdades regionais em múltiplas escalas. A visão tradicional que resumia o problema regional brasileiro ao atraso relativo das Regiões Norte e Nordeste, vistas de forma homogênea, não reconhece nem a existência de dinâmicas sub-regionais diversas em todas as macrorregiões, nem a necessidade de coordenação de ações, com os entes federados e com a sociedade civil, em níveis que vão do intra-urbano ao mesorregional. A ação da Política não se limita à alocação equânime de recursos de origem federal nos territórios; ela reconhece as desigualdades regionais em múltiplas escalas de intervenção e orienta políticas e programas que promovam o desenvolvimento territorial. Busca, ainda, articular políticas setoriais para regiões e sub-regiões prioritárias, sobretudo as de baixa renda, estagnadas e com dinamismo recente, segundo a tipologia proposta pela PNDR (MINISTÉRIO DA INTEGRAÇÃO, 2007, p. 13-14, grifo no original).

\footnotetext{
3 Sobre a guerra fiscal no Brasil consultar Cardozo (2010), Castilho (2012) e Vieira (2012).
} 
Embora a PNDR requeira abordagem em múltiplas escalas,a ênfase em uma Política Nacional é reafirmada, dada a complexidade regional brasileira, afinal, é a escala nacional aquela compatível com a perspectiva de identificação e regulação do fenômeno das desigualdades inter e intrarregionais do país. Em um país continental, federativo, heterogêneo e com marcantes disparidades socioespaciais como o Brasil, a ênfase em soluções localistas isoladas poderia ampliar os riscos de fragmentação.

No campo da política regional, portanto, a situação parecia promissora no início do primeiro mandato de Lula (2003-2006). Uma preocupação especial com o Nordeste Semiárido e com a Amazônia esteve sempre presente nos discursos do presidente eleito.O PPA 20042007 (Brasil de Todos) colocou entre seus objetivos a redução das desigualdades regionais do país.O programa de governo apresentado explicitou o compromisso de formular e implementar uma política nacional de desenvolvimento regional com a perspectiva de constituição de um Fundo Nacional de Desenvolvimento Regional - FNDR, considerado estratégico para consecução dos objetivos traçados. Também se pautou a recriação das superintendências de desenvolvimento extintas em 2001 - Sudam e Sudene.

A proposta da PNDR procurou enfrentar a tendência geral de concentração do capital e contribuir para a "redução das desigualdades regionais" e a "ativação das potencialidades de desenvolvimento das regiões brasileiras". O ponto central da estratégia seria valorizar a diversidade regional do país, em suas múltiplas dimensões - ambiental, socioeconômica e cultural -, e tratá-la como um ativo fundamental para a promoção do desenvolvimento socioeconômico do país. Ela apresentou dois objetivos primordiais: (i) reverter a trajetória das desigualdades regionais, e (ii) explorar os potenciais endógenos da diversificada base regional brasileira. Portanto, a política constituiu-se pelo objetivo da equidade, traduzido na redução das desigualdades de níveis de renda e oportunidades e condições de trabalho, e também pelo objetivo de competitividade, a partir da estruturação de uma base econômica regional capaz de ampliar sua inserção nos mercados nacional e mesmo internacional.

Outro aspecto importante a se destacar é que a atuação em múltiplas escalas buscou romper com a visão tradicional que tende a 
circunscrever o problema regional brasileiro ao Nordeste e Norte. Ou seja, o mapa do Brasil deveria ser dissecado em múltiplas escalas, para fins de política regional, entendendo que cada problema exige uma escala específica de ação e que há, em todo país, área merecedoras de ações públicas. Registre-se que essa visão é solidária aos trabalhos de Araújo (1999) e Galvão e Vasconcelos (1999), que também integraram a equipe do MI que redigiu a proposta da PNDR em 2003.

Para a formatação da tipologia territorial da PNDR e a definição de áreas prioritárias de ação adotou-se a escala microrregional. A base de dados para a classificação das microrregiões compreendeu categorias e informações extraídas dos censos demográficos do Instituto Brasileiro de Geografia e Estatística - IBGE (1991 e 2000) e as estimativas do Produto Interno Bruto - PIB municipal realizadas pelo Instituto de Pesquisa Econômica Aplicada - Ipea para os anos 1990 e 1998. As principais categorias para análise foram: (1) densidade demográfica, (2) crescimento populacional, (3) escolaridade, (4) grau de urbanização, (5) rendimento domiciliar, e (6) variação do PIB (MI, 2003).

Os resultados destacaram o forte contraste litoral versus interior, assim como uma clivagem norte/sul bem marcada, em que se ressaltam profundas diferenças entre os níveis de renda, urbanização e acesso a serviços básicos. Segue uma síntese da avaliação da realidade nacional, em nível microrregional: a) identificação de sub-regiões com elevados rendimentos médios, dinâmicas e competitivas e de sub-regiões com precárias condições de vida e traços de estagnação em todas as macrorregiões do país; b) persistência de um padrão macrorregional expressivo de diferenciação das principais variáveis socioeconômicas entre o Norte-Nordeste e o Sul-Sudeste, com o Centro-Oeste, aproximando-se destas últimas macrorregiões; c) registro da extrema vulnerabilidade dos indicadores socioeconômicos do Nordeste Semiárido e da região amazônica.

Conforme o documento da política (MI, 2003), os dados corroboram a necessidade de se regular as ações de desenvolvimento regional desde a escala nacional, de se pensar estrategicamente as iniciativas no plano macrorregional e em algumas escalas especiais, além de se tratar de modo específico a grande diversidade sub-regional observada. É ressaltada a importância do Nordeste - Semiárido e da região da Faixa de Fronteira como estratégicas para o desenvolvimento 
e a integração nacional. A primeira, por ser tradicionalmente uma subregião com precárias condições de vida e baixa atividade econômica (tinha $40 \%$ da população do Nordeste e respondia por apenas $20 \%$ do PIB regional); a segunda, por ser uma área geopoliticamente fundamental, seja pela questão ambiental, seja pelo objetivo da integração sulamericana, alvo de especial atenção do governo brasileiro. Com o intuito de delimitar os espaços prioritários de ação da PNDR no território nacional, foi proposta a seleção de duas variáveis: rendimento domiciliar médio e variação do PIB. A primeira é uma variável estática que busca mensurar o poder de compra médio em um determinado território, enquanto a segunda, uma variável dinâmica, que mostra a evolução da produção de um determinado espaço geográfico.

A superposição dos cartogramas definidos por essas duas variáveis na escala microrregional, considerada uma composição de sextis agrupados em três conjuntos - alto, médio e baixo -, resultou em quatro conjuntos territoriais distintos. Esses conjuntos territoriais constituiriam a base da tipologia sub-regional que definiria as áreas prioritárias da $P N D R$, conforme se vê no quadro seguinte.

Quadro 2. Tipologia Territorial da PNDR

\begin{tabular}{|c|c|c|c|}
\hline \multirow[b]{2}{*}{$\begin{array}{c}\text { Variação do PIB } \\
\text { 1998/1990 }\end{array}$} & \multicolumn{3}{|c|}{ Rendimento médio por habitante (2000) - \% da média nacional } \\
\hline & $\begin{array}{c}\text { Alto } \\
\text { de } 93 \text { a } 204 \%\end{array}$ & $\begin{array}{c}\text { Médio } \\
\text { de } 33 \text { a } 93 \%\end{array}$ & $\begin{array}{c}\text { Baixo } \\
\text { de } 16 \text { a } 33 \%\end{array}$ \\
\hline $\begin{array}{l}\text { Alta } \\
\text { de } 3,87 \% \text { a } 25,30 \%\end{array}$ & $\begin{array}{l}\text { Alta Renda } \\
\text { (140 } \\
\text { microrregiões) }\end{array}$ & \multicolumn{2}{|c|}{$\begin{array}{l}\text { Dinâmica de baixa renda } \\
\text { (120 microrregiões) } \\
9,0 \% \text { população } 2000 \\
30,3 \% \text { do território } \\
\end{array}$} \\
\hline $\begin{array}{l}\text { Média } \\
\text { de } 3,87 \% \text { a } 0 \%\end{array}$ & $\begin{array}{l}53,7 \% \text { população } \\
12,6 \% \text { do } \\
\text { território }\end{array}$ & $\begin{array}{l}\text { Média renda e } \\
\text { baixo crescimento } \\
\text { (210 microrregiões) } \\
28,9 \% \text { população } \\
33,96 \% \text { do território }\end{array}$ & $\begin{array}{l}\text { Baixa renda e baixo } \\
\text { crescimento } \\
\text { ( } 87 \text { microrregiões) } \\
8,4 \% \text { população } \\
23,26 \% \text { do território }\end{array}$ \\
\hline
\end{tabular}

Fonte: MI (2003).

Os conjuntos de microrregiões (a) dinâmicas de baixa renda, (b) de renda média com baixo dinamismo (estagnadas) e (c) de baixa renda com médio ou baixo dinamismo representam o espaço preferencial de atuação da PNDR, no que respeita ao financiamento dos programas de 
de...

desenvolvimento regional. As áreas de alta renda não seriam alvo de intervenção prioritária para a PNDR.

Em 2013, dez anos após a sua primeira versão, foi lançada a PNDR II. Diferentemente da sua versão original, a PNDR II foi fruto de um amplo debate com a sociedade civil e órgãos de governo, ambientado na I Conferência Nacional de Desenvolvimento Regional - I CNDR. O documento lançado reafirma os princípios da fase I e apresenta quatro objetivos a serem alcançados pela política: a) convergência de renda; b) competitividade regional e geração de emprego e renda; c) agregação de valor e diversificação econômica; d) construção de uma rede de cidades policêntrica.

A Nova PNDR, ou PNDR II, parte do entendimento de que a política regional não logrou alcançar status de política de Estado. Registra-se a necessidade de construir o consenso político e federativo que o encaminhamento da questão regional exige. Há a expectativa de que a PNDR II se transforme em política de Estado após tramitação do seu Projeto de Lei pelo Congresso Nacional ainda em 2015. No entanto, três anos após a I CNDR, observa-se que nada mudou nos rumos da política regional brasileira.

\section{A PNDR E A OPERAÇÃO DOS FUNDOS CONSTITUCIONAIS}

Em termos financeiros, os Fundos Constitucionais de Financiamento constituem o principal instrumento da política regional. O gráfico 1 mostra a firme progressão das suas contratações, especialmente a partir de 2003. Conforme já destacado, esses fundos constituem crédito ao setor produtivo, com atendimento preferencial à MPE e à agricultura familiar, e devem ser reembolsados, embora sob uma taxa de juros subsidiada e sujeita a bônus de adimplência.

\section{Gráfico 1 - Contratações dos Fundos Constitucionais de Financiamento: 1995-2012 (em R\$ milhões, valores constantes de 2010)}




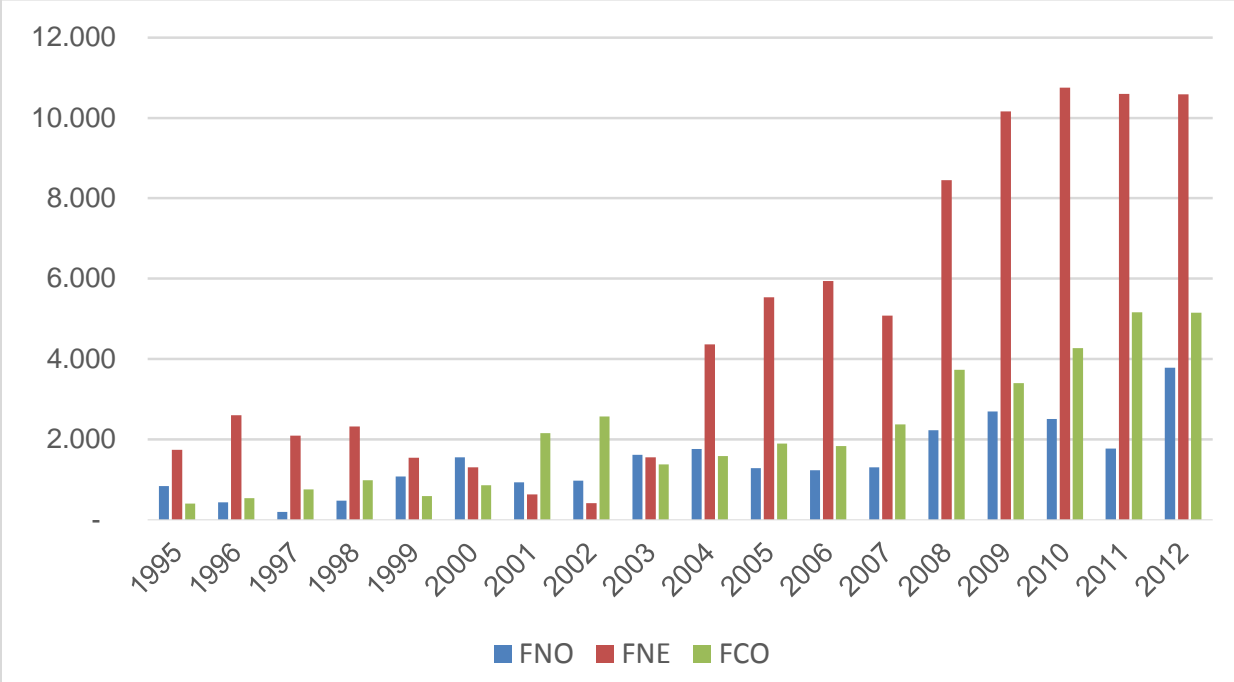

Fonte: MI. Elaboração dos autores.

Gráfico 2 - Fundos Constitucionais de Financiamento: participação em relação ao PIB das regiões Norte, Nordeste e Centro-Oeste (em \%)

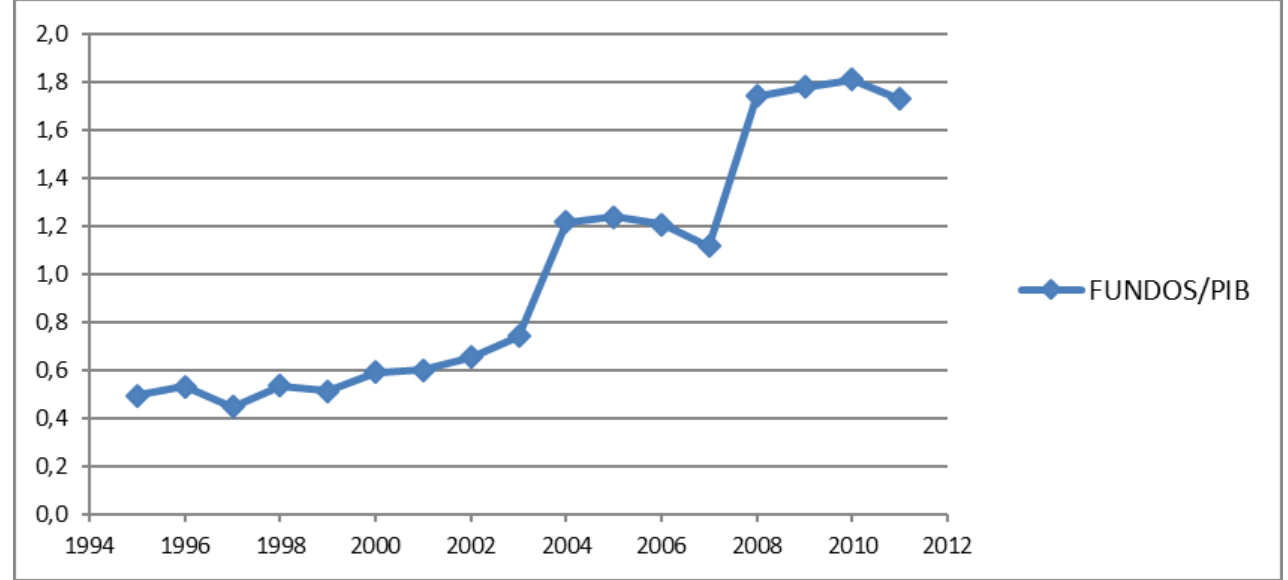

Fonte: MI; IBGE/CONTAS REGIONAIS. Elaboração própria.

O aumento no montante dos valores contratados ampliou a relação entre os Fundos e os PIBs regionais (gráfico 2). Embora essa relação seja muito diferente entre as unidades federativas e oscile bastante ano a ano (MACEDO et al, 2015), o FNO passou de uma relação média de $0,8 \%$ do PIB regional, no período 1995-2002, para 1,3\%, no período pós-2003. Para o $\mathrm{FNE}^{4}$ e FCO, esses números foram, respectivamente, $0,5 \%$ e $1,8 \%$ e $0,5 \%$ e $1,1 \%$. Esses valores, ainda que pequenos, indicam que os três Fundos ampliaram seu papel nos investimentos regionais e passaram a ter maior importância para a

\footnotetext{
4 Estão excluídas as operações contratadas nos estados de Minas Gerais e Espírito Santo, bem como seus respectivos PIBs.
} 
de...

atração ou a viabilização de novos empreendimentos em suas áreas de abrangência ou no acesso ao capital de giro e de custeio para os empreendimentos já constituídos.

Os fundos constitucionais começaram sua operação em 1989, ou seja, bem antes da publicação da PNDR, cuja regulamentação se deu por decreto em 2007. O MI buscou, a partir desse ano, ampliar a aderência da operação dos fundos à PNDR, mas com resultados limitados, como destacado adiante. Nesse sentido, logrou-se aprovar, junto aos conselhos deliberativos dos fundos, resolução que orienta a utilização da tipologia territorial da PNDR como referência para a definição dos limites de financiamento, favorecendo as áreas prioritárias, conforme mostra o quadro 3.

\section{Quadro 3 - Limites de Financiamento dos Fundos Constitucionais e} Tipologia PNDR (em \%)

\begin{tabular}{|l|c|c|c|c|}
\hline \multirow{2}{*}{ PORTE } & \multicolumn{4}{|c|}{ TIPOLOGIAS DA PNDR } \\
\cline { 2 - 5 } & $\begin{array}{c}\text { Baixa Renda e } \\
\text { Baixo Crescimento }\end{array}$ & $\begin{array}{c}\text { Estagnadade } \\
\text { Média Renda }\end{array}$ & $\begin{array}{c}\text { Dinâmica de } \\
\text { Baixa Renda }\end{array}$ & Alta Renda \\
\hline Mini/Micro/Pequeno & 100 & 100 & 100 & 100 \\
\hline Médio & 95 & 90 & 90 & 85 \\
\hline Grande & 90 & 80 & 80 & 70 \\
\hline
\end{tabular}

Fonte: MI.

Sem embargo, a operação dos fundos constitucionais seguiu desassociada das orientações da PNDR no governo Lula (2003-2010) e continuou no primeiro governo Dilma Rousseff (2011-2014). Ironicamente, nas macrorregiões Centro-Oeste e Norte (tabelas 1 e 3), registrou-se aumento relativo das aplicações dos fundos constitucionais nas microrregiões de "alta renda" mesmo após a publicação do Decreto $n^{\circ}$ 6.047/2007, que institucionaliza a PNDR. Na região Nordeste (tabela 2), embora tenha havido queda nas aplicações nas microrregiões de alta renda, houve tendência de concentração dos financiamentos nos municípios de maior porte, além de queda na participação das atividades de menor porte, que são prioritárias tanto nas normativas do FNE quanto nas diretrizes da política regional porte (MACEDO et al, 2015). 
Tabela 1. FNO: Distribuição dos valores contratados segundo tipologias da PNDR (em \%)

\begin{tabular}{|c|c|c|c|c|c|c|c|c|c|c|c|c|c|c|c|c|c|c|}
\hline TIPOLOGIA PNDR & 1995 & 1996 & 1997 & 1998 & 1999 & 2000 & 2001 & 2002 & 2003 & 2004 & 2005 & 2006 & 2007 & 2008 & 2009 & 2010 & 2011 & 2012 \\
\hline Alta Renda & 8,3 & 6,2 & 16,0 & 9,1 & 8,0 & 7,8 & 10,2 & 8,6 & 7,8 & 13,2 & 9,5 & 8,1 & 7,4 & 11,4 & 6,6 & 7,7 & 7,6 & 11,1 \\
\hline Dinâmica & 23,0 & 34,0 & 23,7 & 32,6 & 24,0 & 22,7 & 24,5 & 26,0 & 30,4 & 26,4 & 29,2 & 29,6 & 29,3 & 26,9 & 25,5 & 26,1 & 40,1 & 21,8 \\
\hline Total & $\begin{array}{c}100 \\
0\end{array}$ & $\begin{array}{c}100 \\
0\end{array}$ & $\begin{array}{c}100 \\
0\end{array}$ & $\begin{array}{c}100 \\
0\end{array}$ & $\begin{array}{c}100 \\
0\end{array}$ & $\begin{array}{c}100 \\
0\end{array}$ & $\begin{array}{c}100 \\
0\end{array}$ & $\begin{array}{c}100 \\
0\end{array}$ & $\begin{array}{c}100 \\
0\end{array}$ & $\begin{array}{c}100 \\
0\end{array}$ & $\begin{array}{c}100 \\
0\end{array}$ & $\begin{array}{c}100 \\
0\end{array}$ & $\begin{array}{c}100 \\
0\end{array}$ & $\begin{array}{c}100 \\
0\end{array}$ & $\begin{array}{c}100 \\
0\end{array}$ & $\begin{array}{c}100 \\
0\end{array}$ & $\begin{array}{c}100 \\
0\end{array}$ & $\begin{array}{c}100 \\
0\end{array}$ \\
\hline
\end{tabular}

Fonte: MI. Elaboração própria.

Tabela 2. FNE: Distribuição dos valores contratados segundo tipologias da PNDR (em \%)

\begin{tabular}{|c|c|c|c|c|c|c|c|c|c|c|c|c|c|c|c|c|c|c|}
\hline & & & & & & & & & & & & & & & & & & \\
\hline TIPOLOGIA PNDR & 1995 & 1996 & 1997 & 1998 & 1999 & 2000 & 2001 & 2002 & 2003 & 2004 & 2005 & 2006 & 2007 & 2008 & 2009 & 2010 & 2011 & 2012 \\
\hline Alta Renda & 7,6 & 8,4 & 12,6 & 7,8 & 13,8 & 23,5 & 44,0 & 13,5 & 32,5 & 28,4 & 14,8 & 23,1 & 25,3 & 24,6 & 25,1 & 22,8 & 22,2 & 21,3 \\
\hline Dinâmica & 34,7 & 37,9 & 31,7 & 33,5 & 33,0 & 33,6 & 22,7 & 35,2 & 27,4 & 30,0 & 26,7 & 23,8 & 25,5 & 27,4 & 25,8 & 34,3 & 30,1 & 27,7 \\
\hline Total & $\begin{array}{c}100 \\
0\end{array}$ & $\begin{array}{c}100 \\
0\end{array}$ & $\begin{array}{c}100 \\
0\end{array}$ & $\begin{array}{c}100 \\
0\end{array}$ & $\begin{array}{c}100 \\
0\end{array}$ & $\begin{array}{c}100 \\
0\end{array}$ & $\begin{array}{c}100 \\
0\end{array}$ & $\begin{array}{c}100 \\
0\end{array}$ & $\begin{array}{c}100 \\
0\end{array}$ & $\begin{array}{c}100 \\
0\end{array}$ & $\begin{array}{c}100 \\
0\end{array}$ & $\begin{array}{c}100 \\
0\end{array}$ & $\begin{array}{c}100 \\
0\end{array}$ & $\begin{array}{c}100 \\
0\end{array}$ & $\begin{array}{c}100 \\
0\end{array}$ & $\begin{array}{c}100 \\
0\end{array}$ & $\begin{array}{c}100 \\
0\end{array}$ & $\begin{array}{l}100, \\
0\end{array}$ \\
\hline
\end{tabular}

Fonte: MI. Elaboração própria.

Tabela 3. FCO: Distribuição dos valores contratados segundo tipologias da PNDR (em \%)

\begin{tabular}{|c|c|c|c|c|c|c|c|c|c|c|c|c|c|c|c|c|c|c|}
\hline TIPOLOGIA PNDR & 1995 & 1996 & 1997 & 1998 & 1999 & 2000 & 2001 & 2002 & 2003 & 2004 & 2005 & 2006 & 2007 & 2008 & 2009 & 2010 & 2011 & 2012 \\
\hline Alta Renda & 36,1 & 46,2 & 30,4 & 32,8 & 31,0 & 26,6 & 43,3 & 38,3 & 34,2 & 29,3 & 32,8 & 32,6 & 34,0 & 35,1 & 30,3 & 39,8 & 39,4 & 42,1 \\
\hline Estagnada & 40,2 & 39,3 & 39,1 & 38,5 & 39,4 & 42,4 & 35,3 & 34,5 & 43,3 & 43,0 & 37,7 & 45,7 & 40,1 & 38,8 & 39,8 & 38,2 & 35,3 & 38,3 \\
\hline
\end{tabular}

Fonte: MI. Elaboração própria. 
de...

Tratando dos setores apoiados pelos fundos constitucionais, destaca-se um forte incentivo à agricultura familiar por meio do Pronaf ${ }^{5}$, sobretudo no Norte e Centro-Oeste. Na região Nordeste, entretanto, onde esse segmento representa mais de $50 \%$ da produção regional agropecuária em $2006^{6}$, observou-se perda de participação relativa do FNE na execução do Pronaf que caiu de $23,2 \%$ no período $2003 / 2006$ para $11,4 \%$ no período $2007 / 2010$. Isso demonstra a fragilidade do setor na região Nordeste e a necessidade de novos incentivos e nova institucionalidade para essa atividade de fundamental importância para as populações de baixa renda, particularmente na sua porção semiárida.

É eloquente a questão da região do Semiárido - RSA nessa discussão. De acordo com a Lei $n^{\circ} .7 .827 / 89,50 \%$ dos recursos do FNE deveriam ser aplicados nela. Porém, em função das condições estruturais - o "atraso dentro do atraso"- e dos problemas institucionais apontados por Souza (2012) e por Bastos (2006), esta determinação tem sido reiteradamente descumprida pelo Banco do Nordeste - BNB, gestor financeiro do fundo (ver gráfico 3).

\section{Gráfico 3.FNE: Participação do Semiárido (RSA) no total dos valores contratados (em \%)}

\footnotetext{
5 O PRONAF (Programa Nacional de Fortalecimento da Agricultura Familiar) foi instituído pelo Decreto n. 1.946, de 28 de junho de 1996. A partir da edição da Lei $\mathrm{n}^{\circ}$ 10.177, de 12 de janeiro de 2001, os recursos dos Fundos Constitucionais de Financiamento do Norte, do Nordeste e do Centro-Oeste passaram a compor o funding do Pronaf, com juros, encargos e condições diferenciadas.

6 Fonte: Guanziroli; Di Sabbato e Vidal (2011).
} 


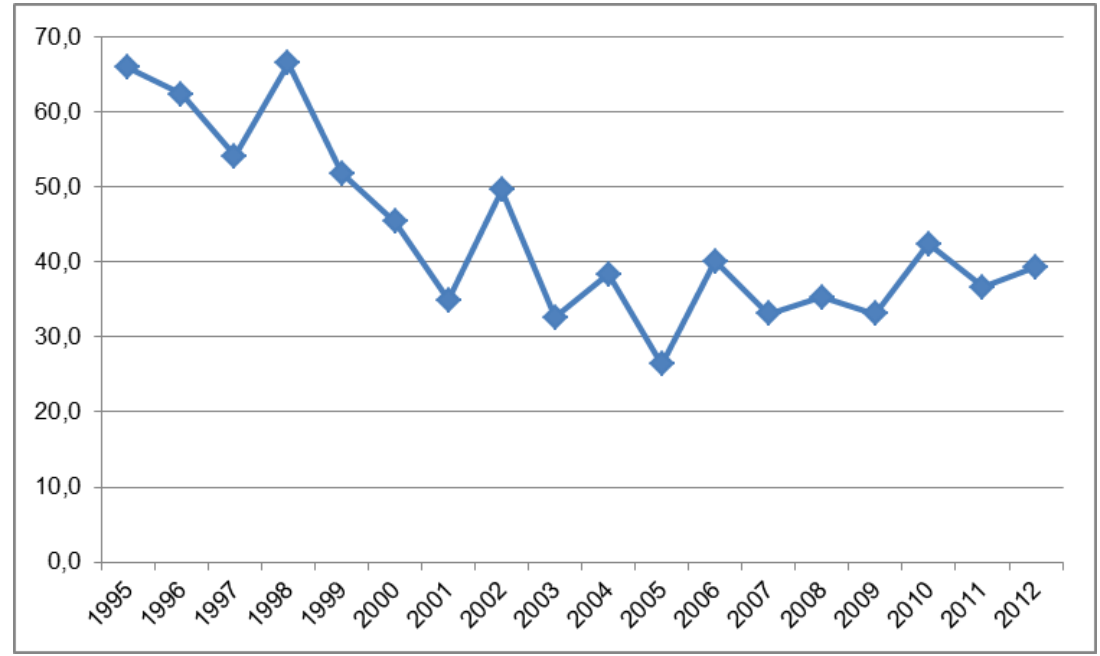

Fonte: MI. Elaboração dos autores.

Pelo gráfico 3, observa-se dois momentos distintos em relação às contratações na RSA. Essas, até 1999, mantiveram-se acima dos 50\%, em consonância com a previsão legal. Cabe destacar que, entre 1995 e 2002, a média total das aplicações dentro da região em destaque foi de 53,9\%. A partir de 2000, essa participação cai para uma média de 35,8\%, com participações bastante variadas, porém sem jamais atingir $50 \%$. Não obstante essa queda relativa, é importante registrar que o volume de recursos direcionados para o RSA cresceu em termos absolutos, acompanhando a evolução do FNE. Basta mencionar que, em 2003, o valor total das contrações na RSA foi de $\mathrm{R} \$ 506,4$ milhões e passou para $\mathrm{R} \$ 4,2$ bilhões em 2012. O número de operações, por sua vez, passou de 13,7 mil em 2003 para 348,5 mil em 2012, confirmando o crescimento no acesso aos recursos do FNE nesta sub-região, sem, contudo, atingir o patamar legalmente estabelecido.

A dificuldade para se cumprir a meta de $50 \%$ dos valores contratados na RSA, uma das áreas prioritárias da PNDR, deve-se ao fato de que o FNE e seus congêneres são uma fonte de financiamento que depende, primordialmente, da demanda dos tomadores, o que reforça a tendência do mercado em canalizar os investimentos para áreas com melhores externalidades que, no caso em questão, são aquelas localizadas na região fora do semiárido - RFSA.

Tabela 4. FNE: Distribuição dos valores contratadas, segundo tipologia da PNDR na RSA e RFSA (em \%)

\begin{tabular}{l|c|c|c|c|c|c}
\hline \multirow{2}{*}{ PNDR } & \multicolumn{3}{|c|}{ RSA } & \multicolumn{3}{c}{ RFSA } \\
\cline { 2 - 7 } & $1995 / 2002$ & $2003 / 2012$ & $2007 / 2012$ & $1995 / 2002$ & $2003 / 2012$ & $2007 / 2012$ \\
\hline
\end{tabular}


de...

\begin{tabular}{l|c|c|c|c|c|c}
\hline Alta renda & 0,7 & 2,3 & 22,4 & 29,7 & 35,2 & 34,6 \\
\hline Dinâmica & 45,2 & 41,1 & 42,9 & 18,3 & 20,9 & 30,6 \\
\hline Estagnada & 35,3 & 42,9 & 28,3 & 28,3 & 29,4 & 26,2 \\
\hline $\begin{array}{l}\text { Baixa } \\
\text { renda }\end{array}$ & 18,8 & 13,7 & 6,5 & 23,7 & 14,5 & 8,6 \\
\hline Total & 100,0 & 100,0 & 100,0 & 100,0 & 100,0 & 100,0 \\
\hline
\end{tabular}

Fonte: MI. Elaboração dos autores.

A situação, no entanto, é mais grave do que o fato do não cumprimento da meta de contratações de empréstimos na RSA. A tabela 4 apresenta a distribuição dos recursos contratados na RSA e na RFSA, segundo a tipologia da PNDR. Paradoxalmente, após a institucionalização da política, na RSA, as contratações para as microrregiões de alta renda - não priorizadas pela política - cresceram em sua participação relativa, o que indica a dificuldade de estimular as atividades prioritárias de qualquer política regional. Para tornar a situação mais preocupante, há queda na participação das microrregiões estagnadas, o que conforma uma dupla situação a merecer reflexão dos policy makers: 1) a dificuldade de fazer os $50 \%$ de recursos para a RSA se contrapor 2) a orientação do mercado, que parece ser ainda mais forte na RSA, na medida que, no período de crescimento das contratações e operações (2003-2012), o financiamento se direcionou, principalmente, para as regiões de alta renda, que são aquelas mais adensadas economicamente. É, na prática, a anti-política regional.

Em síntese, a formalização da PNDR, que supostamente aproximaria a política regional da gestão dos fundos constitucionais, teve pouco ou nenhum impacto sobre suas aplicações no período analisado. A distribuição das aplicações por estados nos períodos 20032006 e 2007-2010 mostra uma aproximação entre o PIB estadual e o volume relativo de aplicações, com exceções pontuais que não desautorizam essa tendência geral. Assim, esse mecanismo financeiro apenas reproduz o quadro socioeconômico vigente no interior das macrorregiões, conclusão já antecipada por outros estudos (MENEZES, 2009; MACEDO e MATOS, 2008). 
Tabela 5. Distribuição dos Fundos Constitucionais por Estados (2003-2010)

\begin{tabular}{|c|c|c|c|c|}
\hline Fundos & Estados & $\begin{array}{c}\text { \% das } \\
\text { Aplicações } \\
(2003-2006)\end{array}$ & $\begin{array}{c}\text { \% das Aplicações } \\
\text { (2007-2010) }\end{array}$ & $\begin{array}{c}\text { \% PIB } \\
\text { Macrorregional } \\
\text { em } 2010 \\
\end{array}$ \\
\hline \multirow{3}{*}{$\mathrm{FCO}^{*}$} & Goiás & 52,35 & 49,41 & 48,62 \\
\hline & Mato Grosso & 26,16 & 29,17 & 29,70 \\
\hline & Mato Groso do Sul & 21,50 & 21,42 & 21,68 \\
\hline \multirow{9}{*}{$\mathrm{FNE}^{* *}$} & Alagoas & 4,69 & 5,20 & 4,84 \\
\hline & Bahia & 31,58 & 25,46 & 30,41 \\
\hline & Ceará & 14,90 & 17,91 & 15,34 \\
\hline & Maranhão & 13,49 & 12,65 & 8,92 \\
\hline & Paraíba & 6,00 & 5,96 & 6,29 \\
\hline & Pernambuco & 11,23 & 14,75 & 18,76 \\
\hline & Piauí & 6,93 & 6,08 & 4,35 \\
\hline & $\begin{array}{l}\text { Rio Grande do } \\
\text { Norte }\end{array}$ & 6,12 & 6,99 & 6,37 \\
\hline & Sergipe & 5,06 & 4,99 & 4,72 \\
\hline \multirow{7}{*}{ FNO } & Acre & 4,87 & 5,71 & 4,21 \\
\hline & Amazonas & 12,03 & 17,09 & 29,67 \\
\hline & Amapá & 0,59 & 3,34 & 4,10 \\
\hline & Pará & 41,53 & 32,74 & 38,63 \\
\hline & Rondônia & 15,76 & 18,57 & 11,69 \\
\hline & Roraima & 2,83 & 1,03 & 3,15 \\
\hline & Tocantins & 22,39 & 21,51 & 8,56 \\
\hline
\end{tabular}

Fonte: Ministério da Integração Nacional

* O DF foi expurgado do cálculo do FCO para evitar a distorção estatística de Brasília, sede do governo federal.

* MG e ES foram expurgados do cálculo do FNE, pois o fundo ampara apenas uma fração dos seus territórios.

Após apresentar a aderência dos Fundos aos objetivos da PNDR, cabe discutir suas operações e o papel dos bancos públicos responsáveis por sua gestão financeira.

\section{CONSIDERAÇÕES SOBRE A OPERAÇÃO DOS FUNDOS CONSTITUCIONAIS}

A partir dos dados apresentados, cabe também questionar o papel dos bancos de desenvolvimento regional - Banco Amazônia AS - Basa, Banco Nordeste - BNB e Banco do Brasil - BB - no fomento ao 
desenvolvimento de suas regiões. Com base na distribuição setorial dos recursos dos fundos constitucionais (tabela 6), observa-se forte tendência de financiamento à agricultura-familiar ou empresarial. $\mathrm{O}$ financiamento à indústria e à infraestrutura é limitado e não alcança $10 \%$ das disponibilidades financeira no âmbito do FCO, e menos de $5 \%$ no do FNO, no período analisado. 
Tabela 6. Distribuição dos Fundos Constitucionais por Setores (2003-2010)

\begin{tabular}{|c|c|c|c|}
\hline Fundos & Setor & $\begin{array}{c}\text { \% das Aplicações } \\
(2003-2006)\end{array}$ & $\begin{array}{c}\text { \% das Aplicações } \\
(2007-2010)\end{array}$ \\
\hline \multirow{5}{*}{ FCO } & $\begin{array}{l}\text { Agricultura Familiar } \\
\text { (PRONAF) }\end{array}$ & 42,53 & 42,03 \\
\hline & Agronegócio & 45,97 & 29,89 \\
\hline & Comércio e Serviços & 8,89 & 20,18 \\
\hline & Industrial & 2,56 & 7,84 \\
\hline & Infraestrutura & 0,04 & 0,06 \\
\hline \multirow{5}{*}{ FNE } & $\begin{array}{l}\text { Agricultura Familiar } \\
\text { (PRONAF) }\end{array}$ & 23,19 & 11,46 \\
\hline & Agronegócio & 27,04 & 27,72 \\
\hline & Comércio e Serviços & 15,48 & 22,91 \\
\hline & Industrial & 21,26 & 20,12 \\
\hline & Infraestrutura & 13,03 & 17,80 \\
\hline \multirow{5}{*}{ FNO } & $\begin{array}{l}\text { Agricultura Familiar } \\
\text { (PRONAF) }\end{array}$ & 36,50 & 42,95 \\
\hline & Agronegócio & 55,21 & 34,86 \\
\hline & Comércio e Serviços & 4,07 & 18,55 \\
\hline & Industrial & 4,20 & 2,67 \\
\hline & Infraestrutura & 0,03 & 0,97 \\
\hline
\end{tabular}

Fonte: Ministério da Integração Nacional.

O fomento à atividade industrial é tarefa essencial dos bancos de desenvolvimento, seja pelo incentivo ao beneficiamento da produção local, seja pela geração de mais e melhores empregos, seja para diversificar a economia regional e gerar encadeamentos internos (backward e forward linkages), seja para amenizar o peso relativo da exploração agropecuária sobre os sensíveis ecossistemas regionais Amazônia, Semiárido e Cerrado.

Para lembrar Hirschman (1961), a falta de interdependência e de encadeamento nos sistemas de produção é comum em países subdesenvolvidos. A agricultura em geral, e a agricultura de subsistência em especial, são caracterizadas pela escassez de efeitos em cadeia, mas o apoio a elas deve ser mantido em decorrência de aspectos sociais envolvidos, especialmente no caso da agricultura familiar, e pela importância do setor para a dinâmica das economias regionais no Brasil. No entanto, a superioridade da manufatura e dos serviços mais sofisticados a esse respeito é maior, o que milita contra 
de...

qualquer alternativa de especialização agrícola para os países subdesenvolvidos.

Por isso, é uma agenda importante de pesquisa discutir o papel dos bancos de desenvolvimento, cuja criação associou-se à estruturação de suas economias regionais. Devem ser evitadas redundâncias, pois, caso prevaleça esse papel de fomento à economia primária da forma como se encontra hoje, incumbência já exercida por outros bancos a partir do crédito agrícola, os bancos de desenvolvimento regional apenas incorrem em sombreamento institucional, negligenciando suas missões institucionais precípuas ou, pelo menos, diminuindo suas eficácias na busca pelo desenvolvimento regional.

Um exemplo disso. Tomando por base as três maiores economias agrícolas da região Nordeste, observa-se que no Maranhão, em Pernambuco e na Bahia, que responderam, no período 2003 a 2012, por quase $2 / 3$ do valor de produção da agricultura do Nordeste (lavouras temporárias mais permanentes), o montante das contratações do FNE se concentrou em suas microrregiões com agricultura mais dinâmica ligada à expansão da soja (casos do Maranhão e Bahia7) e à fruticultura de exportação (caso de Pernambuco) que já contam com outras linhas de financiamento, especialmente em relação aos tomadores de maior porte.

Essa concentração dos recursos nas microrregiões mais dinâmicas ocorre tanto para os tomadores de grande porte quanto para os de pequeno porte, conforme se observa nas figuras 1 e 2 , embora, para estes, haja melhor distribuição espacial dos financiamentos. Isso confirma o fato de o FNE - e também os outros dois fundos - seguirem uma tendência pró-mercado, reforçando a concentração intraregional e intraestadual, ainda que cumpra importante papel na desconcentração inter-regional. Com efeito, a agenda do desenvolvimento regional subjaz esquecida no presente cenário.

Figura 1. FNE: Distribuição dos recursos contratados no setor agrícola, segundo tomadores de pequeno porte (em R\$) - Período 2003/2012

\footnotetext{
7 O mesmo ocorre com os financiamentos para a expansão da soja no cerrado piauiense.
} 

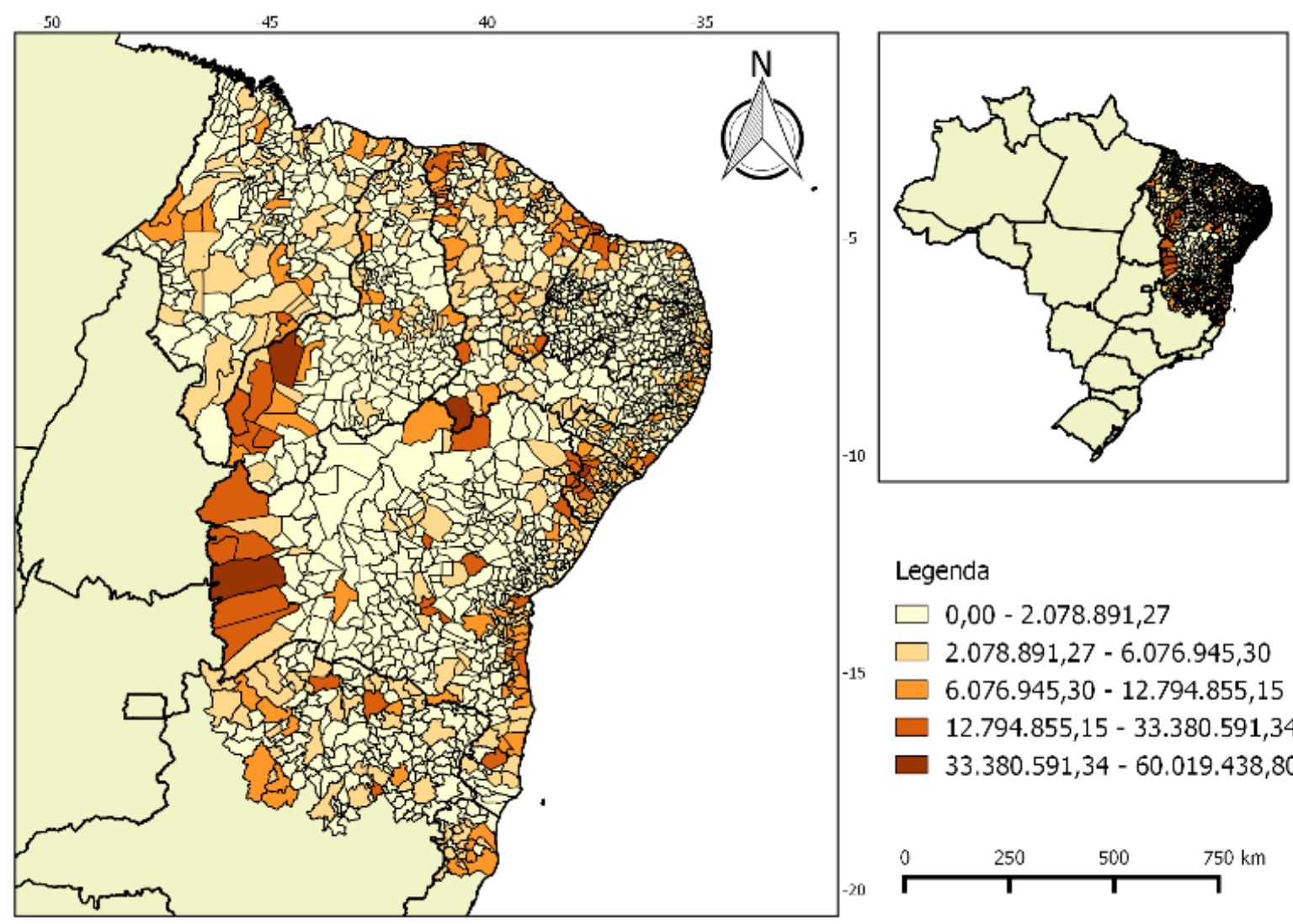

Legenda

$\square 0,00-2.078 .891,27$

- 2.078.891,27- $6.076 .945,30$

$\square 6.076 .945,30-12.794 .855,15$

$\square 12.794 .855,15-33.380 .591,34$

- 33.380.591,34 - 60.019.438,80

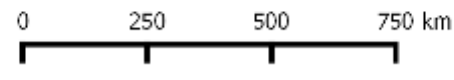

Fonte: MI. Elaboração: Daniel P. Sampaio. 
de...

Figura 2. FNE: Distribuição dos recursos contratados no setor agrícola, segundo tomadores de grande porte (em R\$) - Período 2003/2012
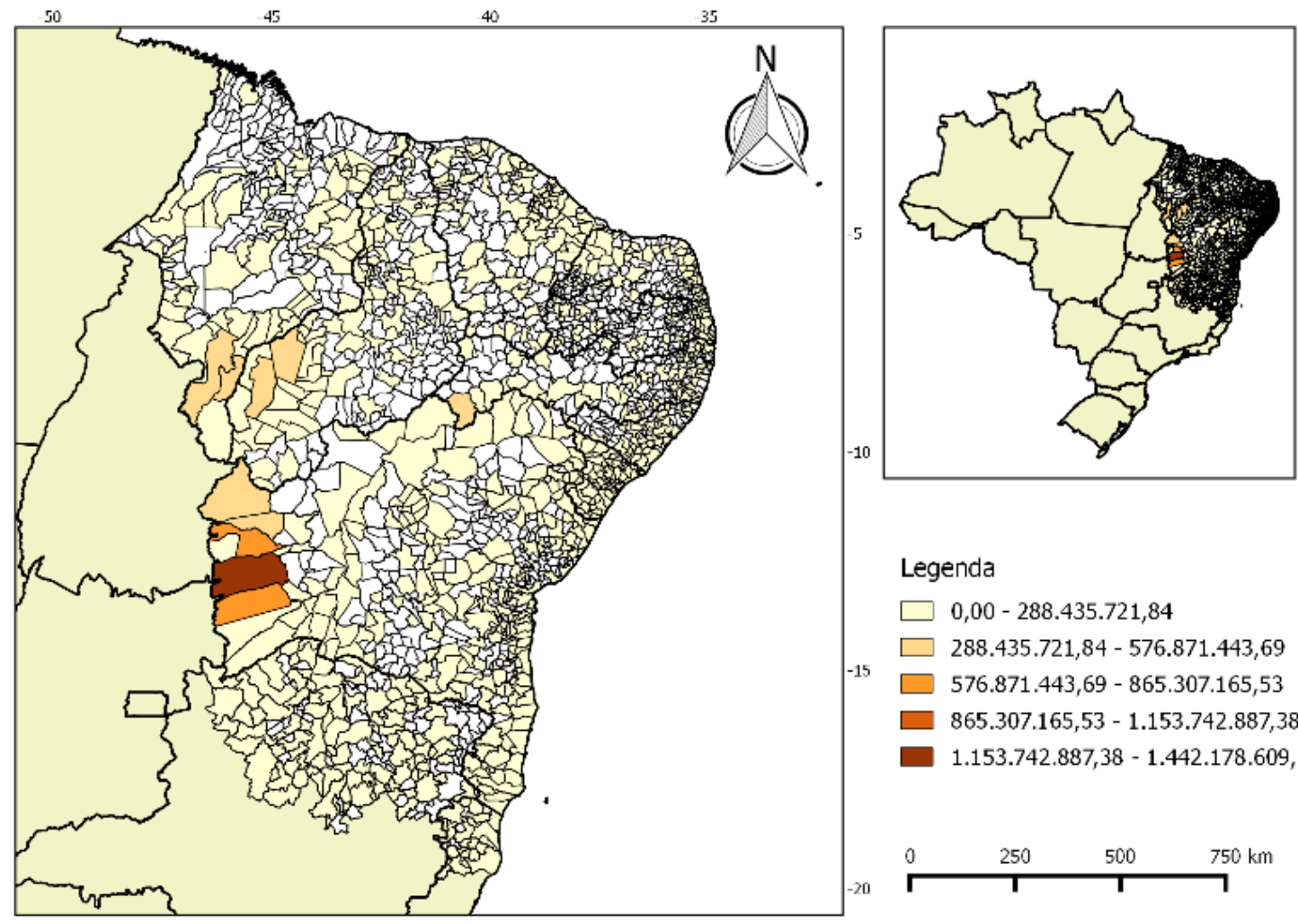

\section{Legenda}

$\square 0,00-288.435 .721,84$

$\square 288.435 .721,84-576.871 .443,69$

$\square 576.871 .443,69-865.307 .165,53$

$\square 865.307 .165,53-1.153 .742 .887,38$

$\square 1.153 .742 .887,38-1.442 .178 .609,22$

Fonte: MI. Elaboração: Daniel P. Sampaio.

Como se vê, não é desprezível a disponibilidade de recursos para as políticas regionais no Brasil. Porém, como já foi assinalado, esses instrumentos - fundos constitucionais, fundos de desenvolvimento e incentivos fiscais - foram criados antes da edição da PNDR e sua aderência à política foi praticamente nula. Em outras palavras, são instrumentos desassociados de uma política de desenvolvimento regional, e muito mais ainda de um projeto nacional de desenvolvimento. Eles atendem a interesses setoriais que buscam se beneficiar das vantagens creditícias e tributárias oferecidas. Ademais, foram concebidos considerando a divisão macrorregional do país, enquanto a PNDR prioriza a atuação em múltiplas escalas, com certa ênfase microrregional.

O MI publica, anualmente, portarias com diretrizes e orientações gerais para definição de prioridades e aprovação de projetos de investimentos com recursos dos fundos constitucionais e dos fundos de desenvolvimento. Essas portarias devem orientar a programação de investimentos desses fundos para o exercício seguinte, apontando 
setores estratégicos, áreas preferenciais, vedações etc. Desde a edição do Decreto $n^{\circ}$. 6047/2007, que formaliza a PNDR como política de governo, essas portarias do MI fazem menção à PNDR como critério de seletividade espacial na programação das ações dos fundos constitucionais e de desenvolvimento.

Essas portarias têm determinado que as programações desses fundos concedam "tratamento diferenciado e favorecido aos espaços reconhecidos como prioritários pela PNDR: mesorregiões diferenciadas da PNDR; Regiões Integradas de Desenvolvimento - Ride; faixa de fronteira; microrregiões classificadas pela tipologia da PNDR como de baixa renda, dinâmicas ou estagnadas". Sem embargo, nenhuma meta quantitativa é apresentada e tampouco se qualifica o que seria esse tratamento diferenciado e favorecido. Portanto, a influência normatizadora da PNDR sobre os fundos constitucionais e de desenvolvimento no período analisado foi, no mínimo, questionável.

Cabe mencionar, nesse ínterim, o relatório emitido pelo Tribunal de Contas da União - TCU a respeito da PNDR (TCU, 2009). O TCU elegeu o Desenvolvimento Regional como o Tema de Maior Significância no período 2009-2010 e realizou um conjunto de auditorias com o objetivo de conhecer a PNDR, seus instrumentos e seus mecanismos de financiamento, que englobaram cerca de $R \$ 20$ bilhões em cada exercício, considerando-se, além dos recursos orçamentários diretamente associados à política, os fundos constitucionais e de desenvolvimento regional.

Entre as conclusões do TCU, destacam-se: (i) falhas no direcionamento de recursos em relação às diretrizes e prioridades estabelecidas pela PNDR; (ii) ausência de indicadores e metas quantitativas, inclusive para direcionar a distribuição de recursos por regiões prioritárias da PNDR; (iii) falhas relacionadas à falta de estrutura ou processos de trabalho para o desempenho da missão institucional das entidades vinculadas à execução da PNDR.

Para sanar tais problemas, o TCU emitiu o acórdão 2.919/2009, com uma série de recomendações à Casa Civil da Presidência da República, ao Ministério da Integração Nacional e ao Ministério do Planejamento, no sentido de se construir maior aderência dos instrumentos de política regional à PNDR, porém pouco se avançou nesse sentido até agora. 
Alguns estudos (MACEDO e MATOS, 2010; MENEZES, 2009; MACEDO et al, 2015) concluem que a atuação dos fundos constitucionais e dos incentivos fiscais resulta na ampliação das desigualdades intrarregionais no interior das macrorregiões. Com efeito, a demanda qualificada por crédito e por incentivos fiscais tende a ser mais acentuada nas sub-regiões mais dinâmicas dos estados favorecidos - sobretudo no entorno das grandes capitais e dos enclaves exportadores. É a lógica da causação circular cumulativa (MYRDAL, 1968) em operação nos espaços periféricos do país sob o patrocínio dos instrumentos de política regional que supostamente deveriam atuar na contramão desse processo.

Cabe lembrar que os fundos discutidos representam crédito ao setor produtivo, devendo ser reembolsados, ainda que sob uma taxa de juros subsidiada e sujeitos a bônus de adimplência; esse crédito está essencialmente voltado ao empreendedor privado. Entretanto, uma política nacional de desenvolvimento regional envolve um conjunto de questões que transcendem a perspectiva do entrepreneur.

Do ponto de vista microeconômico, seriam necessárias ações estruturantes e complementares, essenciais ao desenvolvimento regional, exempli gratia, provisão de infraestrutura, sobretudo de pequeno e médio portes, conservação ambiental, formação profissional e apoio à ciência, à tecnologia e à inovação. Em regiões de baixa renda, tais iniciativas podem apresentar taxas internas de retorno inicialmente negativas e, por isso, deveriam ser financiadas por aportes não reembolsáveis. Essa foi a grande motivação para a criação do FNDR, pensado como o principal instrumento de intervenção da PNDR, mas que nunca fora efetivado.

Do ponto de vista macroeconômico, seria necessária a soberania na condução da política econômica, permitindo a manutenção de baixas taxas de juros, de uma taxa de câmbio favorável à produção nacional e de uma política fiscal comprometida com o crescimento. Sobretudo, seria necessário um projeto nacional que orientasse a estratégia e as ações da PNDR e que não ficasse engessado pela política macroeconômica como tradicionalmente tem ocorrido no período pós1980. Sem essa orientação, os instrumentos financeiros da política regional seguiram "a reboque" das demandas setoriais, sobretudo dos setores intensivos em recursos naturais e de baixo conteúdo 
tecnológico, vinculados à exportação de commodities agrícolas e minerais.

Macedo (2010) lembra que a agropecuária e a indústria extrativa vêm sendo importantes vetores para a configuração urbano-regional do país, reforçando especializações regionais e levando a adaptações do território para articular as produções locais descentralizadas ao mercado externo. Essas regiões, ao se articularem mais fortemente com o exterior, em um contexto de baixo crescimento interno, tornaram o espaço nacional mais heterogêneo, marcado pela presença de poucas áreas dinâmicas ligadas ao mercado internacional, que convivem com outras de menor dinamismo ou mesmo estagnadas. Nesses termos, não deixa de ser preocupante o fato de os fundos constitucionais de financiamento reforçarem essa tendência ao apoiar enclaves nas áreas de maior dinamismo, cuja lógica exportadora não tem gerado encadeamentos significativos para a economia regional.

Em tempo, é de suma importância salientar que as grandes "regiões-problema" do país, seja a Amazônica Legal, seja o Nordeste Semiárido, exigem, necessariamente ações inovadoras e criativas para o seu desenvolvimento. Trata-se de territórios ambientalmente sensíveis que não podem ser tratados com base na exploração intensiva de commodities de base agropecuária ou mineral. Essa percepção já havia sido apontada pelo relatório do Grupo de Trabalho para o Desenvolvimento do Nordeste - GTDN, coordenado por Celso Furtado, em 1959.

Nessas regiões, importa desenvolver iniciativas inovadoras, de baixo impacto ambiental, o que demanda substanciais investimentos em ciência e tecnologia e pesquisa e desenvolvimento. Essa estratégia permite a agregação de valor das produções regionais e o adensamento de suas cadeias produtivas, gerando mais e melhores ocupações, baseadas em setores diferenciados, com maior capacidade de absorção de progresso técnico.

A introdução do progresso técnico na agricultura familiar e nos regimes extrativistas tradicionais permitiria explorar o magnífico potencial de nossa biodiversidade, seja no desenvolvimento de sistemas de produção de alimentos e energia solar na RSA, seja no desenvolvimento de medicamentos fitoterápicos e exploração do potencial produtivo da região amazônica. Vale dizer que a produção de 
de...

alimentos e medicamentos fitoterápicos conta com mercados institucionais relevantes, graças às compras governamentais do Programa Nacional de Aquisição de Alimentos - PAA e do Sistema Único de Saúde - SUS.

Sob uma perspectiva hirschmaniana, tem-se, aqui, a possibilidade de desenvolver forward e backwards linkages nas economias regionais periféricas a partir de redes de fornecimento e comercialização, assistência técnica, financiamento e beneficiamento para os múltiplos sistemas de produção possíveis. Esse adensamento da produção enseja o desenvolvimento de economias de aglomeração e o florescimento de novas centralidades urbanas, provedoras de serviços especializados, na lógica policêntrica defendida por Diniz (MPOG, 2008).

Não é desprezível o impulso à industrialização derivado da introdução do progresso técnico nas periferias nacionais, mediante o incentivo ao beneficiamento das produções primárias regionais. Como indica Furtado (1992), a industrialização, ao articular em um mesmo sistema econômico regiões que antes se vinculavam ao exterior, contribuiu de forma decisiva para consolidar a formação nacional do Brasil. Conforme Coêlho (2014), à diferença da ação pulverizada das iniciativas localistas ou dos enclaves exportadores, cujos impactos sobre a vida das populações locais têm sido desprezíveis - ou mesmo nocivos -, a estratégia sugerida comporta possibilidades promissoras para o desenvolvimento regional brasileiro. Um novo motor de crescimento econômico baseado na integração desses complexos regionais está ao alcance da civilização brasileira.

No entanto, dado o isolamento relativo de certas regiões, sobretudo na Amazônia Legal, é necessário investir em sistemas criativos de fornecimento de serviços de energia, telecomunicações, transportes, saúde e educação em áreas de baixa densidade populacional e difícil acesso. Permanece o imperativo do projeto nacional que planeje e organize as diversas ações necessárias no domínio do desenvolvimento regional, seja no campo da educação básica, da saúde pública, do provimento de tecnologias, infraestrutura e crédito.

\section{CONCLUSÕES}


Quando se observa o financiamento da PNDR - e este é um ponto central para sua eficácia - ficam evidentes suas dificuldades. Toda arquitetura financeira da política de desenvolvimento regional no Brasil fora concebida antes dela. Os principais instrumentos foram estruturados para atuarem macrorregionalmente nas tradicionais "regiões-problema".

Por essa razão, a constituição do FNDR foi, desde a concepção inicial da PNDR, considerada estratégica para sua execução em múltiplas escalas e com participação dos entes federativos. Entretanto, conforme consta em documentos do $\mathrm{Ml}$, a proposta de criação do FNDR se perdeu e se inviabilizou no quadro de impasses da própria Proposta de Emenda Constitucional que tratava da reforma tributária.

Portanto, as dificuldades da reforma tributária - uma velha demanda da sociedade e que poderia reordenar as fontes e usos dos fundos públicos - tornaram-se óbice para se avançar nessa pauta. Qualquer reforma tributária pressupõe alterar a correlação de forças da Federação e estabelecer outra pactuação com definição de perdedores e vencedores, nacional e regionalmente. Isso esbarraria, evidentemente, na reação dos grupos de interesses hegemônicos que atuam por dentro dos fundos públicos - incluído neles o FNO, o FNE e o FCO - e que exercem forte poder político local, regional e nacional. Sem esta reforma, no entanto, será muito difícil redefinir o financiamento da política regional brasileira, tanto nacionalmente, como por exemplo, a criação do FNDR, quanto em nível subnacional com a persistência da guerra fiscal.

Para melhorar a aderência dos Fundos Constitucionais de Financiamento à PNDR, no entanto, não basta equacionar o financiamento, mas adequar, concomitantemente três questões: 1) a condução da política macroeconômica de forma a não obstaculizar os objetivos das diversas políticas setoriais, visto que aquela tende a colocar dificuldades a estas, no caso específico, à própria PNDR; 2) nas regiões prioritárias importa desenvolver iniciativas inovadoras, de baixo impacto ambiental, o que demanda substanciais investimentos em ciência e tecnologia e pesquisa e desenvolvimento, para os quais poderiam ser utilizados os recursos disponíveis para a política regional. Essa estratégia permite a agregação de valor das produções regionais e o adensamento de suas cadeias produtivas, gerando mais e melhores 
de...

ocupações, baseadas em setores diferenciados, com maior capacidade de absorção de progresso técnico; 3) romper a lógica de mercado presente nos fundos constitucionais e direcionar proativamente recursos que adensem infraestruturalmente municípios que possam cumprir papel de centros sub-regionais e liderar redes de cidades capazes de suportar a desconcentração produtiva no Brasil.

Como visto, há limitada aderência entre os objetivos da PNDR e as aplicações dos Fundos Constitucionais de Financiamento. São exemplos, conforme destacado, o aumento relativo das aplicações dos FNO e do FCO em microrregiões de "alta renda" ou a queda de participação relativa das atividades de menor porte nos desembolsos do FNE. Como se sabe, as atividades de menor porte são prioridade dentro da política regional. Isso sem contar com o fato de os financiamentos na RSA ficarem sistematicamente abaixo dos $50 \%$ constitucionalmente previstos para aplicação do FNE. Essa também é uma área considerada prioritária na PNDR. Por essas razões, e outras anteriormente destacadas, considera-se que a lógica desses fundos segue os determinantes do mercado, beneficiando regiões com maiores vantagens comparativas.

Para superar esses problemas, é preciso repensar tanto a PNDR e seus instrumentos de intervenção quanto a gestão dos fundos e as formas de financiamento que não podem ficar restritas à escala macrorregional e subordinadas apenas à lógica do mercado. A PNDR demanda, dentre outras coisas, um fundo de desenvolvimento regional de abrangência nacional que possa ser operado em múltiplas escalas, em todas as regiões do país, incentivando atividades econômicas estratégicas e inovadoras, capazes de contribuir para a inclusão produtiva e o adensamento do tecido socioeconômico das regiões mais atrasadas.

\section{REFERÊNCIAS}

ARAÚJO, T. B. de. Por uma Política Nacional De Desenvolvimento Regional. Revista Econômica do Nordeste, Fortaleza, v. 30, n. 2, p. 144161, abr.-jun 1999.

ALVES, A. M.; ROCHA NETO, J. M. A Nova Política Nacional de Desenvolvimento Regional - PNDR II: entre a perspectiva de inovação e a 
persistência dos desafios. Revista Política e Planejamento Regional, Rio de Janeiro, v. 1, n. 2, p. 311-338, jul-dez/2014.

ALVES, A. M.; ROCHA NETO, J. M.; AMPARO, P. P. Política regional brasileira: retrospectiva e novos rumos. Revista Brasileira de Desenvolvimento Regional, Blumenau, v. 2, n.2, p. 107-132, 2014.

BASTOS, F. Ambiente institucional no financiamento da agricultura familiar. São Paulo: Polis; Campinas-SP: Ceres, 2006.

BRANDÃO, C. Avançamos a PNDR II, mas falta transformá-la em uma estratégia de Estado. Revista Política e Planejamento Regional, Rio de Janeiro, v. 1., n. 2, p. 339-344, jul-dez/2014.

CARVALHO, O. Perspectiva do desenvolvimento regional no Brasil. Revista Política e Planejamento Regional, Rio de Janeiro, v. 1, n. 2, p. 295-310, jul-dez/2014.

CARDOZO, S. A. Guerra Fiscal no Brasil e alterações nas estruturas produtivas estaduais nos anos 1990. 2010. 315 fls. Tese (Doutorado em Desenvolvimento Econômico) - Instituto de Economia, Universidade Estadual de Campinas, Campinas, 2010.

CASTILHO, F. R. C. Alterações Constitucionais de ICMS, Guerra Fiscal, Competição tributária e melhora do Ambiente de Negócios no Brasil. São Paulo: editora Quarter Latin do Brasil, 2012

CINTRA, M. A. M. Fundos Constitucionais de Financiamento (do Norte, Nordeste e do Centro-Oeste. Projeto de Pesquisa O Brasil na era da globalização: condicionantes domésticos e internacionais ao desenvolvimento (Subprojeto IX: Crédito direcionado e desenvolvimento econômico no Brasil: o papel dos fundos públicos). Campinas: Instituto de Economia/UNICAMP, 2007.

COÊLHO, V. L. C. AEsfinge e o Faraó: a política regional do governo Lula (2003-2010). Tese (Doutorado em Desenvolvimento Econômico). Instituto de Economia, Universidade Estadual de Campinas, Campinas, 
2014.

COSTA, L. S. G. M. Fundos Federais - um diagnóstico. Brasília: Secretária do Tesouro Nacional ( $4^{\circ}$ Prêmio SOF de Monografia), 2011.

GALVÃO, A. C. F. e VASCONCELOS, R. R. Política Regional à escala SubRegional: uma tipologia Territorial como Base para um fundo de apoio ao Desenvolvimento Regional. Brasília, IPEA, Texto Para Discussão $N^{\circ}$ 665, 1999.

GUANZIROLI, C. E.; DI SABBATO, A.; VIDAL, M. F. Agricultura familiar no nordeste: uma análise comparativa entre dois censos agropecuários. Fortaleza: Banco do Nordeste do Brasil, 2011.

FURTADO, C. Brasil:a construção interrompida. Rio de Janeiro, Paz e Terra, 1992.

HIRSCHMAN, A. O. Estratégia do desenvolvimento econômico. Rio de Janeiro: Ed. Fundo de Cultura, 1961.

MACEDO, F. C. Notas sobre as políticas de desenvolvimento regional segundo as Constituições Federais do Brasil e o papel dos Fundos Constitucionais de Financiamento pós-1988. Revista Brasileira de Desenvolvimento Regional, Blumenau, v. 2, p. 19-47, 2014.

MACEDO, F. C. Inserção Externa e Territórios: impactos do comércio exterior na dinâmica regional e urbana no Brasil (1989-2008). Tese (Livre-Docência). 2010. Tese (Livre Docência) - Instituto de Economia, Universidade Estadual de Campinas, Campinas, 2010.

MACEDO, F. C. et al. Diagnóstico da aplicação dos recursos dos Fundos Constitucionais de Financiamento. Brasília, IPEA. Relatório de Pesquisa, 2015.

MACEDO, F. C; MATOS, E. N. O papel dos Fundos Constitucionais de Financiamento no desenvolvimento regional brasileiro. In: HANSEN, D. L.; SANTANA, J. R. TEIXEIRA, O. A. (Org.). Estratégia de desenvolvimento regional - conceitos e experiências. Aracaju: Editora da UFS, v.1, p. 123- 
154, 2010.

MENEZES, A. R. A. de. A utilização indutora de incentivos fiscais como mecanismo de redução de desigualdades regionais: análise acerca de sua (in) efetividade à luz do modelo de Estado e do projeto político de desenvolvimento insculpido na CF de 1988. Dissertação de Mestrado Universidade Federal de Pernambuco, Recife, 2009.

MINISTÉRIO DA INTEGRAÇÃO NACIONAL. Política Nacional de Desenvolvimento Regional. Brasília, Ministério da Integração Nacional, 2003.

MINISTÉRIO DO PLANEJAMENTO, ORÇAMENTO E GESTÃO. Secretaria de Planejamento e Investimentos Estratégicos - SPI. Estudo da Dimensão Territorial para o Planejamento: Volume IV - Estudos Prospectivos Escolhas Estratégicas. Brasília, MPOG, 2008.

MYRDAL, G. Teoria Econômica e Regiões Subdesenvolvidas. Rio de Janeiro, Ed. Saga, 1968.

RESENDE, G. M.10 anos da Política nacional de Desenvolvimento Regional (PNDR). Boletim ODR - Observatório do desenvolvimento Regional, Brasília, n.1, p. 65-74, out-dez/2014. Disponível em http://www.integracao.gov.br/c/document_library/get_file?uuid=a616d 4b2-7f6a-4731-b406-0d9f27cbb014\&groupld=1411172 .

SOUZA, R. C. de. Efeitos da Previdência Rural na Agricultura Familiar da Microrregião Serra de São Miguel-RN. Natal-RN, 2012, 146 f. Dissertação (Programa de Pós-Graduação em Estudos Urbanos e Regionais) - Universidade Federal do Rio Grande do Norte, Natal, 2012.

TRIBUNAL DE CONTAS DA UNIÃO. Relatório de Levantamento do Programa de Promoção da Sustentabilidade de Espaços Sub-Regionais PROMESO. TC n. ${ }^{\circ} 010.604 / 2009-0$ Fiscalis n. ${ }^{\circ} 420 / 2009,26$ p. Brasília, 2009.

VIEIRA, D. J. Um estudo sobre a Guerra Fiscal no Brasil. 2012. 218 fls. 
A Política Nacional de Desenvolvimento Regional - PNDR e os Fundos Constitucionais

de...

Tese (Doutorado em Desenvolvimento Econômico) - Instituto de Economia. Universidade Estadual de Campinas, Campinas, 2012.

Submetido em 16/06/2015

Aprovado em 02/012/2015

\section{Sobre os autores}

\section{Fernando Cezar de Macedo}

Professor livre-docente do Instituto de Economia da Unicamp.

Endereço: Universidade Estadual de Campinas, Instituto de Economia. Cidade Universitária Zeferino Vaz, Barão Geraldo. 13083970 - Campinas - SP - Brasil.

E-mail: fcmacedo@eco.unicamp.br

\section{Vitarque Lucas Paes Coelho}

Doutor em Desenvolvimento Econômico (IE/UNICAMP) e gestor de políticas públicas do Ministério da Integração Nacional.

Endereço: Ministério do Planejamento, Orçamento e Gestão - Esplanada dos Ministérios. 70040-906 - Brasilia - DF - Brasil.

E-mail:vitarque@yahoo.com.br 